\title{
A Study on the Fracture Strength of the Cement Gap
}

\author{
Woon Seon Kwak, Chung Jae Lee \\ Department of Oral Health Graduate School of Public Health, Dankook University, Shin Han University, Republic of korea
}

This research is conducted for better clinical test of ZIRCONIA as we find out the fracture strength difference of Zirconia on cement gaps of FULL CROWN that made use of Zirconia which is somewhat being used in recent dental technology. We produced each nine of Zirconia Crown of Zirconia fracture cement gaps (0.03)A group, (0.05)B group, (0.08)C group on cement gaps by use of CAD/CAM, and compared the results. We could end up getting conclusions as following: There was fracture strength difference per cement gaps but no impact $(\mathrm{p}<0.05)$. There was difference between $1.962 \pm 0.259$ from group A and $2.005 \pm 0.367$ from group B, but no impact ( $\mathrm{p}<0.05$ ). There was difference between $1.962 \pm 0.259$ from group A and 2.478 \pm 0.331 from group $\mathrm{C}$, but it's hard to consider as an impact $(\mathrm{p}<0.05)$. Because of the higt pressure $0.08 \mathrm{~mm}$ is fracture as well as Margin has a lot of empty space due to Gap for $0.08 \mathrm{~mm}$. To identify the difference between $0.08 \mathrm{~mm}$ and $0.05 \mathrm{~mm}, 0.08 \mathrm{~mm}$ is selected as a Gap. Therefore when it come to use $0.05 \mathrm{~mm}$ authentically 0.05 is quite practical to use as a Gap

Methods: We produced each nine of Zirconia Crown of Zirconia fracture cement gaps A group (0.03 mm), Bgroup (0.05 mm), $\mathrm{C}$ group $(0.08 \mathrm{~mm})$ on cement gaps by use of CAD/CAM, and compared the results. We couldend up getting conclusions as following.

\begin{tabular}{|c|c|c|c|c|c|c|}
\hline Material and Equipment & Product & Manufacture & & & & \\
\hline CAD/CAM system & EXO CAD & Italy & & & & \\
\hline 3D Scanner & Medit & Korea & & & & \\
\hline Milling Machine & Roland & Japan & & & & \\
\hline Model & Nissin(D51DP-500A-MF) & Japan & & & & \\
\hline Zirconia & Brux & USA & & & & \\
\hline Instron & UTM 4303 & USA & & & & \\
\hline Metal & REX N ALLOY & USA & & & & \\
\hline \multirow{2}{*}{ Group } & & All data & & \multicolumn{3}{|c|}{ Data except $\min \& \max$} \\
\hline & $\mathrm{N}$ & $\mathrm{M} \pm \mathrm{SD}$ & & $\mathrm{N}$ & $\mathrm{M} \pm \mathrm{SD}$ & \\
\hline A & 9 & $1.692 \pm 0.259$ & $b$ & 7 & $1.930 \pm 0.144$ & $b$ \\
\hline B & 9 & $2.005 \pm 0.367$ & $\mathrm{~b}$ & 7 & $2.075 \pm 0.147$ & $\mathrm{~b}$ \\
\hline C & 9 & $2.478 \pm 0.331$ & a & 7 & $2.478 \pm 0.331$ & a \\
\hline $\mathrm{P}^{*}$ & \multicolumn{3}{|c|}{0.004} & \multicolumn{3}{|c|}{$<001$} \\
\hline
\end{tabular}

"p-value by one-way ANOVA test

A: group with $0.03 \mathrm{~mm}$ gap

B: group with $0.05 \mathrm{~mm}$ gap

Results: There was fracture strength difference per cement gaps but no impact $(\mathrm{p}<0.05)$. There was difference between 1.962 0.259 from group $A$ and 2.0050 .367 from group $B$, but no impact $(\mathrm{p}<0.05)$. There was difference between 1.9620 .259 from group A and 2.4780 .331 from group $C$, but it $s$ hard to be considered as an impact $(\mathrm{p}<0.05)$.

Conclusion: Because of the hight pressure $0.08 \mathrm{~mm}$ is fractured and Margin has a lot of empty space due to gap for $0.08 \mathrm{~mm}$. To identify the difference between $0.08 \mathrm{~mm}$ and $0.05 \mathrm{~mm}, 0.08 \mathrm{~mm}$ is selected as a gap. Therefore when it comes to using $0.05 \mathrm{~mm}$ authentically $0.05 \mathrm{~mm}$ is quite practical to use as a gap.

Copyright (C) 2021. Korean Academy of Preventive Dentistry. All rights reserved.

This is an Open Access article distributed under the terms of the Creative Commons Attribution Non-Commercial License (http://creativecommons.org/licenses/ by-nc/4.0) which permits unrestricted non-commercial use, distribution, and reproduction in any medium, provided the original work is properly cited. 